June - 2007

\title{
Setting the New Standard with Mobile Computing in Online Learning
}

\author{
Yuhsun Edward Shih and Dennis Mills \\ Capella University, USA
}

\begin{abstract}
Mobile learning represents exciting new frontiers in education and pedagogy. With the features of 'wearable' computing and multimedia content delivery via mobile technologies, mobile learning becomes feasible and offers new benefits to instructors and learners. How do mobile technologies influence our teaching and learning in traditional education? What are the possibilities for $\mathrm{m}$ Learning in the various disciplines, such as history or English studies? To illustrate these possibilities, this paper presents an application that combines an innovative learning model for mobile learning with an established literature class. This ongoing study focuses on student learning outcomes relative to the benefits and challenges of using mobile technologies in a traditional classroom and online learning settings.
\end{abstract}

Keywords: Mobile learning; learning model; instructional design; hybrid course; motivation

\section{Introduction}

Mobile communication technologies are rapidly evolving to include local area wireless connections using Wi-Fi, Third Generation (3G) mobile communications, and Worldwide Interoperability for Microwave Access (WiMAX), and related mobile computing devices such as smart phones, pocket PCs, tablet PCs, and various Personal Data Assistants (PDAs) handheld devices. As such, applying mobile technologies in learning represents an exciting new frontier in education and pedagogy. With the capabilities of 'wearable' computing and multimedia content delivery via mobile technologies, learning with mobile technologies becomes feasible because it offers many new benefits, such as ubiquitous learning that connect instructors and learners in both traditional classroom and online settings. As Alexander (2004) suggests, "the combination of wireless technology and mobile computing is resulting in an escalating transformation of the educational world” (p. 1).

There are many different learning theories that address how people learn, such as behaviorism, cognitivism, constructivism, control theory, learning styles, and social learning. While implementing mobile learning, it is necessary to consider - at minimum - the following aspects of new mobile technologies: a) new learning opportunities; b) potential influence on changing individuals' learning styles; c) potential influence on social interaction; and d) how the mobile technology itself will be changed or enhanced. How individuals learn and how learning takes place are essential considerations for instructional designers, especially in designing learning 
Setting the New Standard with Mobile Computing in Online Learning

Shih \& Mills

activities in the mobile learning environment. Unfortunately, at the present time many individuals enter this field with no pedagogical guidelines, and based on existing research findings this has become a major issue. How can we better utilize mobile technologies to improve teaching and learning in education? How can we effectively motivate and engage online learners? This paper proposes a new mobile learning model identified as the Shih's Mobile Learning Model. The goal of Shih's model is to facilitate mobile learning design and to achieve better mobile learning outcomes. From a pedagogical point of view, this paper supports understanding of mobile learning and facilitates the instructional design for applying mobile technologies to a traditional learning context.

\section{Mobile Technologies in Education}

Internationally, mobile technologies are on the cutting edge of business applications. Widespread use of mobile phones, PDAs, MP3 players, handhelds, tablet PCs, and laptops for learning, working, meeting, and conferencing is evident. The academic environment has been introduced to mobile learning through the use of laptops, PDAs, and smart phones. Research outcomes reported in Attewell's (2005) summary of the 2001 MLearn project, suggest that the use of mobile learning may have positive contributions to make in the following areas:

1. Mobile learning helps learners to improve their literacy and numeracy skills and to recognise their existing abilities

2. Mobile learning can be used to encourage both independent and collaborative learning experiences

3. Mobile learning helps learners to identify areas where they need assistance and support

4. Mobile learning helps to combat resistance to the use of ICT and can help bridge the gap between mobile phone literacy and ICT literacy

5. Mobile learning helps to remove some of the formality from the learning experience and engages reluctant learners

6. Mobile learning helps learners to remain more focused for longer periods

7. Mobile learning helps to raise self-esteem

8. Mobile learning helps to raise self-confidence (Attewell, 2005, p. 13)

Mobile technologies are the next step in the evolution of technology-mediated teaching and learning. It not only connects people in information-driven societies effectively, it offers the opportunity for a spontaneous, personal, informal, and situated learning. Mobile technologies have sparked the need for the strategies, applications, and resources necessary to support anywhere-anytime connections to formal and situational learning, as well as personal interest explorations (Wagner, 2005). On the other hand, is mobile learning viewed as a technological consideration in delivery systems? Or does it represent a new pedagogy in education? Thomas (2005, p. 9) posed the question: "How can this m-Learning environment change teaching and learning?" Thomas further suggested that wireless connections provide attractive learning environments in a number of ways: 
1. Ubiquity: Faculty and students have access to course information 24 hours a day, 365 days a year, wherever they are on campus

2. Project sophistication: Student projects created with laptops tend to be more sophisticated

3. Compatibility: Students have access to the same hardware and software as faculty

4. Emphasis on learning and teaching: Overcoming equipment problems allows greater time and resources to be devoted to pedagogy

5. Savings: Replacing desktop computers with laptops, and replacing hard-wired networks with wireless ones translates into cost savings

6. Standardization: A standard platform maximizes access and minimizes need for technical support (Thomas, 2005, p. 9)

Mobile computing and wireless connections are accelerating transformations in the educational world, such as seen in the rapid development of new delivery platforms for teaching and learning. The impact of mobile learning in higher education is that ". . . the physical vs. the digital, the sedentary vs. the nomadic - the wireless, mobile, student-owned learning impulse cuts across our institutional sectors, silos, and expertise-propagation structures" (Alexander, 2004, p. 34). The culture of education is changing as new avenues are redefining the old. Information literacy enhanced by technology has the capacity to deepen the roots of education while expanding knowledge and information literacy. It may change the structure of how students experience learning. Therefore, it is important to continue to grow the roots of education while exploring new approaches to learning through technology (Alexander, 2004).

The following characteristics define how mobile technologies are currently improving online learning environments. The capabilities for learning anytime and anywhere, just in time, just for me, and multimedia (text, voice, image, or video) messaging are essential characteristics. The use of various types of communication (i.e., phone call, voice/ text messaging, multimedia messaging, email, Web access), that provide real-time online interaction in a series of short burst learning activities, with features such as voice/ video recording for story telling or even a 'mobblogging' journal, complete the roster of characteristics that define effective use of mobile technologies in teaching and learning.

As technology continues to improve, it will be possible to integrate even more features into smart phones, and with the likelihood of several different types of small handheld devices, such as Ultra Mobile Personal Computers (see Figure 1 below). Consumers can expect mobile computing with handheld devices to offer an affordable solution to their learning needs in the classroom, in the lab, at home, or for outdoor activities. Mobile technologies positively influence today's teaching and learning, in both formal and informal settings. 
Figure 1. Ultra Mobile Personal Computer (Source: Fourier Systems http://www.fouriersys.com)

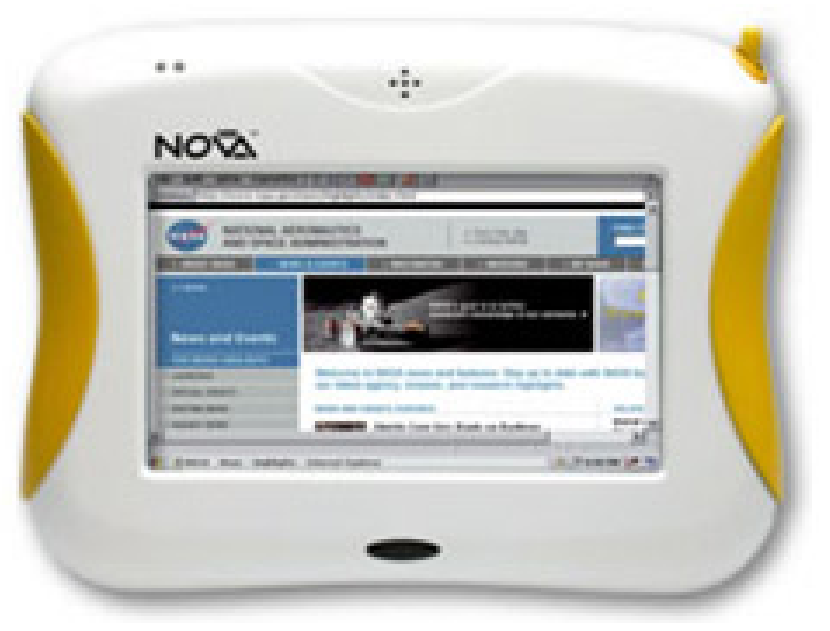

\section{Toward a New Learning Model}

In contrast to the traditional classroom, mobile technologies effectively offer students added convenience and flexibility, and allows them to learn wherever and whenever they choose. In situations where mobile technologies are integrated into a classroom environment, there are opportunities to soften the rigidity of the standard classroom arrangement because each learner is "connected" wherever they choose to be in that learning space. Outside the classroom, learners will be able to continue their studies in spaces that meet their individual needs. Mobile technologies empower learners to conveniently participate in learning environments.

How individuals learn and how learning takes place are essential considerations for instructional design, especially in teaching and learning with mobile technologies. Several different learning theories address how people learn, such as behaviorism, cognitivism, constructivism, and so forth (Smith, 1999). Behaviorism, for example, applies drill-and-practice strategies to achieve learning that results in a change in the learner's behavior. Behaviorists focus on the output of the learning process by frequently reinforcing concepts with examples, interactions, and practices. Meanwhile, cognitivism focuses on how the mind works. Cognitivists believe that the working process of the mind should be exploited to enhance the learning process. Control theory is the theory of motivation which states that behavior is inspired by what a person desires most at any given time, such as love, freedom, power, survival, or other basic human needs. Constructivism, on the other hand, suggests that people construct their knowledge by experiencing things and reflecting on those experiences. Constructivists encourage students to use experiments and problem solving skills to create more knowledge and to reflect on how their understanding is changing. The objective of using reflection is to encourage students to reflect upon and learn from their experiences and conclusions.

The learning styles theory emphasizes that individuals perceive and process information in very different ways, and that individuals learn more when the educational experience is geared toward their particular learning styles. Instructors can introduce a wide variety of experiential elements into the learning environment, such as sound, music, visuals, movement, and even gaming. Instruction should be designed to connect with multiple learning styles (i.e., visual, auditory, 
kinesthetic), using various combinations of experience, reflection, conceptualization, and experimentation. Vygotsky's learning theory emphasizes that learning is social and includes arguing, reflecting, and articulating to others (Vygotsky, 1978). Learning occurs through interaction between learners and learning tasks. Social cognition provides learning from a dialectical process, whereby students can learn through problem-solving experiences shared with their learning peers (Riddle \& Dabbagh, 1999).

Among these learning theories, learning styles and Vygotsky's are more relevant to supporting mobile learning activities. Most mobile devices are capable of taking pictures, capturing video, and playing music. Mobile technologies can effectively fit into different learning styles by providing picture-video messaging, audio-video conferencing, and 3-D simulation gaming to enhance learners' experiences. It also provides users with effective ways for communicating and accessing learning contents at anytime and anyplace, via phone calls, instant messaging, email, and Web access. These features can facilitate group interactions for collaborative learning by helping students share their information and experiences. Similar to control theory, mobile technologies motivate learners through the use of automatic instant messaging or content forwarding, the so-called "push technologies." In a mobile learning environment, learners can repeatedly practice learning content anytime and anywhere. This feature of learning has similarities to the behaviorism learning theory. Considering how people learn with all these features, the next step is to put it all together.

\section{The New Standard for Mobile Learning}

According to Keller's ARCS Model of motivational design, the learning cycle includes: Attention, Relevance, Confidence, and Satisfaction (ARCS). Keller also determined that motivation was the most appropriate and useful construct that might be applied to the problem of variation in learning performance difference, and that motivation was dependent at least, in part, on human interactions (Keller, 1987). In the ARCS model of motivation, the initial phase is to attract learners by stimulating their interest and curiosity. This can involve the use of interesting facts or statistics, conflict, humor, audience participation, variability, and questions. The second phase is designed to show learners the relevance of their learning, so that their motivation to learn increases. This can be accomplished by providing examples, previous experiences, concepts, and presenting goal-orienting statements. The third phase allows learners to develop their confidence. This can be achieved by setting realistic expectations, providing opportunities for practice, and elevating the contents' difficulty to increase learner independence for completion. The final phase provides opportunities for learners to use their newly acquired skills and/ or knowledge in a real or simulated setting. Reinforcement sustains the desired learning behavior, which can produce true satisfaction.

Based on ARCS learning model and mobile technologies' characteristics in promoting and enhancing human interactions, a variation to the ARCS model, the Shih's Mobile Learning Model (see Figure 2), was created to support instructional design for mobile learning. The learning cycle in the Shih's model includes:

1. Sending a multimedia message to mobile phones to trigger and motivate learners

2. Searching the Web for relating information by using embedded hyperlinks (URLs) in the message received in the phone

3. Discussing with learning peers by text, voice, picture, or video messaging 
4. Producing a digital story telling of what they learn by audio or video diary (mobblogging journal)

5. Applying what they learn in the simulated environment, such as online educational gaming

Figure 2. Learning Cycle in Shih’s Mobile Learning Model

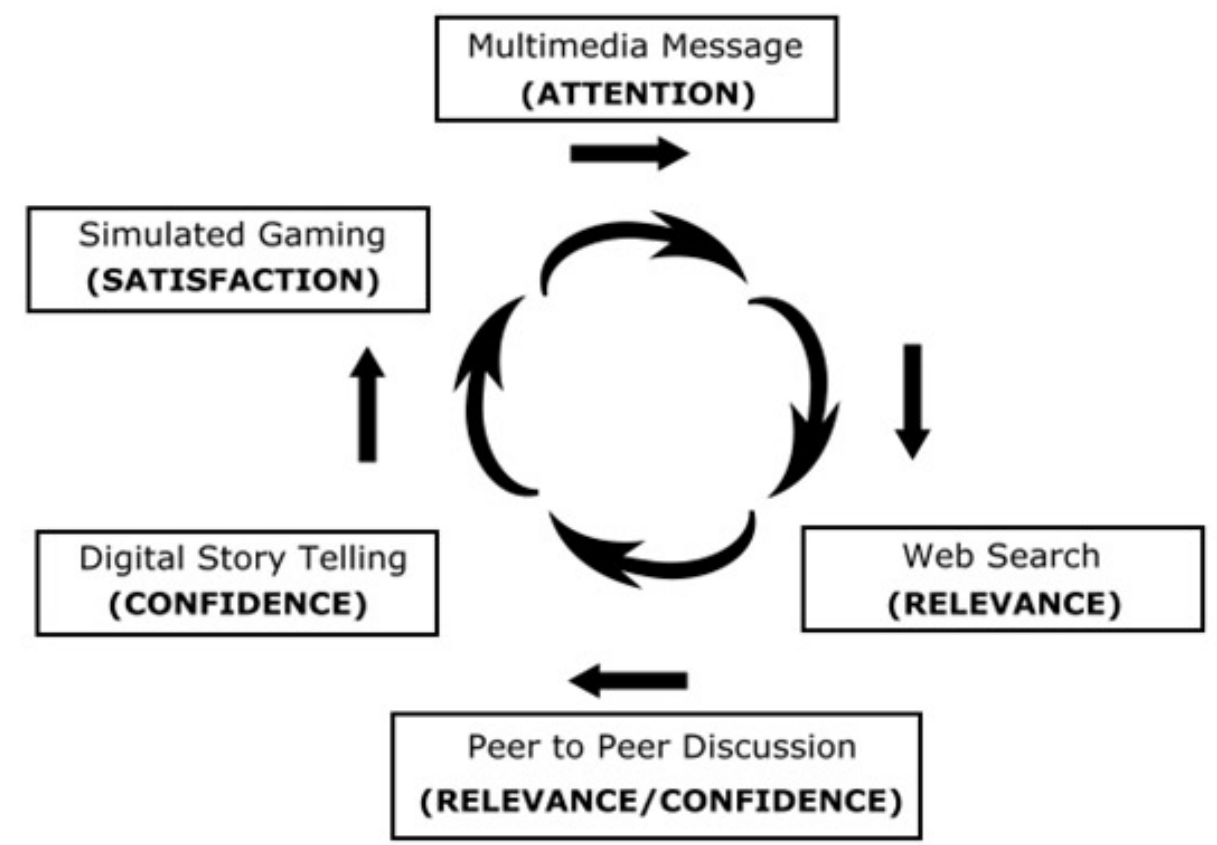

Shih's mobile learning model draws on the philosophy of social constructivism through use of collaborative discussion and a learning styles theory based on digital story telling. Elements of the Vygotsky learning theory are incorporated in Shih's model through peer learner interactions via mobile communication. This learning model mainly relies on the mobile computing infrastructure, and would be most suitable for applications in blended learning and/ or pure mobile learning environments (Shih, 2005).

\section{Research Experiment}

An experiment of applying Shih's mobile learning model was conducted in a Children's Literature hybrid course in California State University, San Bernardino during the 2006 winter semester. Forty-six $(n=46)$ students participated in this experiment. The course provided students flexibility to use their smart phones to access mobile learning contents located on a mobile website (http://mclass.m-learning.us), receive learning activity notifications via text messages, join online discussions with fellow students via the regular online learning site (http://www.m-learning.us), and produce digital stories for their course learning activities.

The hypothesis and intention of this project was to apply mobile technologies to offer participants added convenience and flexibility, arguably two very valuable assets for most commuter student 
populations. The study focused on students' learning outcomes, as well as the benefits and challenges students face when using mobile learning in a traditional classroom setting. We anticipated that mobile learning would provide an additional and useful method of information retrieval and reception needed to further facilitate collaborative learning. With an appropriate instructional design used to adapt mobile learning methods in the course, we expected that students would be able to better utilize their time for learning, and be more motivated and active in their learning.

To illustrate these possibilities, we presented an application in an enhanced Moodle Course Management System that provided mobile learning capability with an established literature class. We also demonstrated Shih's model, which was used to apply new mobile technologies to a traditional learning context. The learning units were designed to be completed within a fairly small period of time. For instance, students could take a quiz or interpret an illustration while standing in line at the bank, while they are stuck in traffic, or any other situation where a standard computer would be impractical. Short messages (SMS) were sent to students to engage them in or in many cases, push them forward - in their group projects. Students were encouraged to use their smart phones for creating the digital story telling course projects. In addition, an assessment was built into the study that allowed students to gauge their own readiness for mobile learning.

We began with the following questions:

1. First, and perhaps most importantly, how would our students initially receive the idea of completing part of their coursework on a PDA/ smart phone?

2. Would they find the m-Learning techniques helpful and manageable, or would they view learning in a new medium as an additional burden?

3. What instructional design techniques are needed in mobile learning courses to allow for the limitations of a particular mobile technology?

The survey of the experiments generated some interesting findings. For instance, one of the greatest difficulties was the availability of appropriate mobile phones. For representative statistical charts created from this experiment, see Figures 3-11 in the Appendix.

When compared to purely online learning courses, this preliminary study also found the following:

1. Students were more highly motivated (they said they appreciated the flexibility and convenience)

2. Interaction between the instructor and students was more enhanced

3. Students appeared to be more encouraged to collaborate

4. The instruction was more attractive to students

5. Quality of learning was found to be 'as good' or 'better'

Within this model, the instructor had a better chance to observe and assist students who need extra support; this was accomplished by applying adaptive learning instructions. This model 
substantially improved students' overall online learning experiences and helped them to achieve better learning outcomes. This study also revealed additional challenges the instructor faced when receiving student responses and feedback on his or her mobile learning device. The study also revealed the need for support of mobile learning within the wider university culture.

\section{Future Work}

Future mobile teaching and learning strategies will need to explore how mobile learning can continue the improvement of overall learning outcomes. Further study is also needed to involve a 'control group' to compare the learning results and to determine whether or not the above findings are supported or rejected.

In addition, following areas are of special concern:

1. Mobile technologies come with limitations for use in educational settings, such as different form factors in mobile devices, communication coverage, and potential security issues. For instance, what instructional design strategies are needed in m-Learning courses that better address limitations of mobile technologies?

2. Mobile learning provides "just in time" help and "just for me" features that supports various learning styles. How can instructional design be individualized to support students with special needs?

3. Messaging capabilities are, such as SMS and multimedia messages, are some of the most powerful "push" features of mobile technologies. However, while it is evident that such push communication can effectively facilitate and motivate learners in collaborative learning activities, it may also intrude upon students' personal space. Therefore the question must be asked: What new 'netiquette' and instructional design strategies are needed?

4. Social implications in the progress and development of mass communications, plus related cost factors may lead to (in)accessibility issues in mobile learning. How can we maximize the potential of mobile technology in educational contexts, without creating another digital divide?

\section{Conclusion}

Advancements in technologies have changed the process of learning, not just in formal educational settings, but continuing education settings as well. With the use of mobile technologies in education, online learning communities can incorporate students from different backgrounds with vastly diverse learning styles into a education setting. Motivating online students, as well as learning how to effectively facilitate learning in this format, is essential for developing successful online learning communities. The use of mobile technologies also incorporates a new concept for teaching and learning in this environment.

Today, we live in an information era, a world where technology, economics, society, politics, and theories of learning are all in a state of transition. This competitive environment suggests that theories, definitions, and the practice of distance learning will continue to be contested. In this competitive environment, it is evident that mobile learning has a range of attributes that cannot be ignored because it is highly portable, personal, and contextual. Learning using mobile devices is 
Setting the New Standard with Mobile Computing in Online Learning

Shih \& Mills

informal, spontaneous, situated, and ubiquitous. When comparing mobile learning to online learning using desktop computers, it becomes evident that mobile learning comes with many advantages and some drawbacks. Varied and changing locations, the ability for more immediate interaction with teachers and fellow students, and the portability and affordability of smaller, handheld wireless devices, coupled with their capacity to accomodate learners from different backgrounds, make mobile devices a logical choice for educators. Therefore, as mobile learning moves into the educational mainstream, the need for appropriate pedagogical instructional design models, teaching strategies, learning styles, and effective learning activities, will remain crucial to ubiquitous mobile learning environments.

Shih's Mobile Learning Model is a new instructional design model; it helps instructional designers motivate and engage online learners and instructors, which in turn enhances their online teaching and learning experiences. By focusing on the use of mobile technologies in educational contexts, Shih's model provides an innovation in instructional design that guides the use of enhancements for effective teaching and learning in today's virtual m-Learning environments.

\section{References}

Alexander, B. (2004). Going Nomadic: Mobile learning in higher education. EDUCAUSE Review 39(5), 28-35. Retrieved September 14, 2005 from: http://www.educause.edu/ir/library/pdf/erm0451.pdf

Attewell, J. (2005). Mobile Technologies and Learning: A technology update and m-learning project summary. London: Learning and Skills Development Agency.

Keller, J. M. (1987). Development and use of the ARCS model of motivational design. Journal of Instructional Development, 10(3), 2-10.

Riddle, E., \& Dabbagh, N. (1999). Lev Vygotsky's Social Development Theory. Retrieved June 6, 2005 from:

http://chd.gse.gmu.edu/immersion/knowledgebase/theorists/constructivism/vygotsky.htm.

Shih, Y. E. (2005). Seize Teachable and Learnable Moments: SMSE instructional design model for mobile learning. Paper presented at the International Association for Development of the Information Society International Conference Mobile Learning June 28-30, Malta.

Smith, M. K. (1999). Learning theory, the encyclopedia of informal education. Retrieved June 6, 2005 from: www.infed.org/biblio/b-learn.htm

Thomas, M. (2005, May 23). E-learning on the move. Education Guardian online. Retrieved June 10, 2005 from: http://education.guardian.co.uk/elearning/comment/0,10577,1490476,00.html

Vygotsky, L. S. (1978). Mind in Society: The development of higher psychological process. Cambridge, MA.: Harvard University Press.

Wagner, E. D. (2005). Enabling mobile learning. EDUCAUSE Review, 40(3), 40-53. Retrieved June 4, 2005 from: http://www.educause.edu/ir/library/pdf/erm0532.pdf 


\section{Appendix}

Figure 3. Mobile PDA Phone availability survey

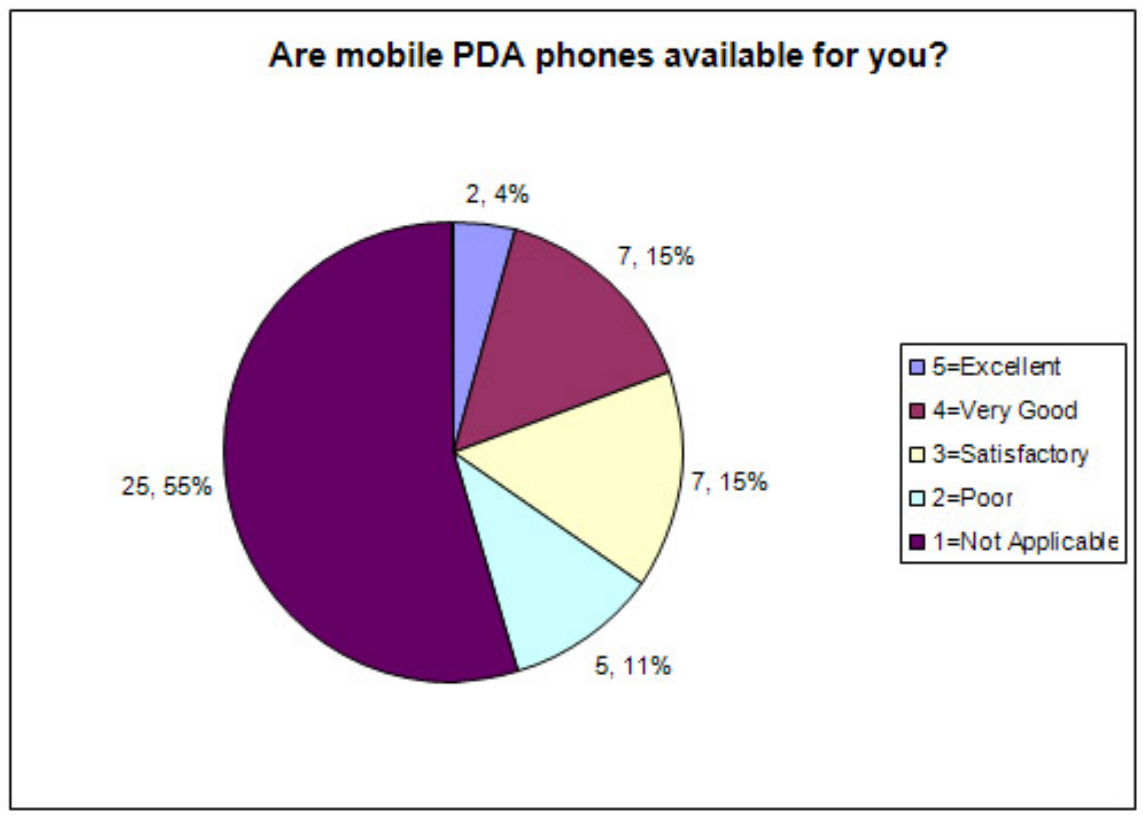

Figure 4. Mobile learning outcomes survey

Does use of PDA Mobile phones help you save time?

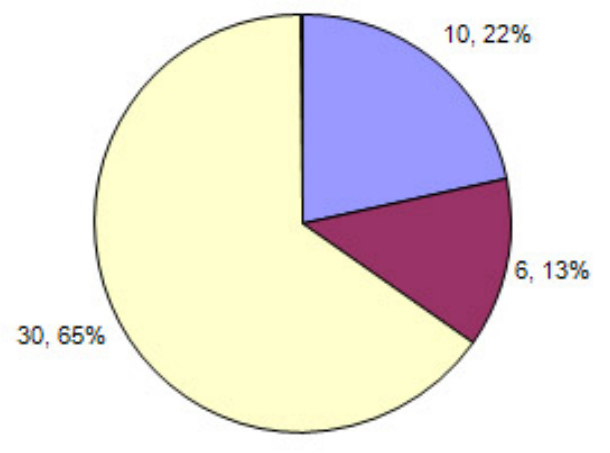

aYes

$\square$ No

$\square$ No application 
Figure 5. Mobile learning outcomes survey

Increased your knowledge of mobile learning and other uses of technology in the classroom

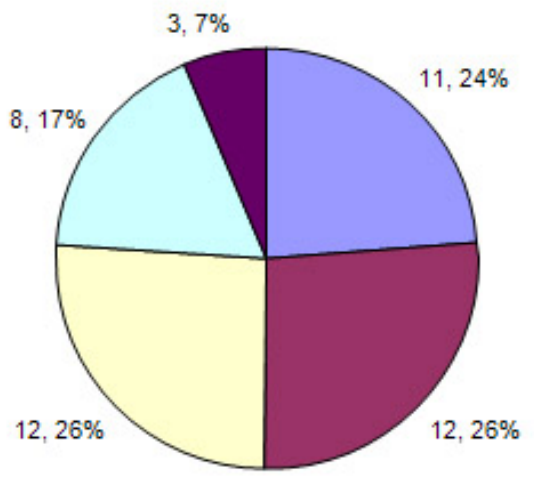

$\square 5=$ Excellent

$\square$ 4=Very Good

$\square$ 3=Satisfactory

$\square 2=$ =Por

口 1=Not Applicable

Figure 6. Mobile learning outcomes survey

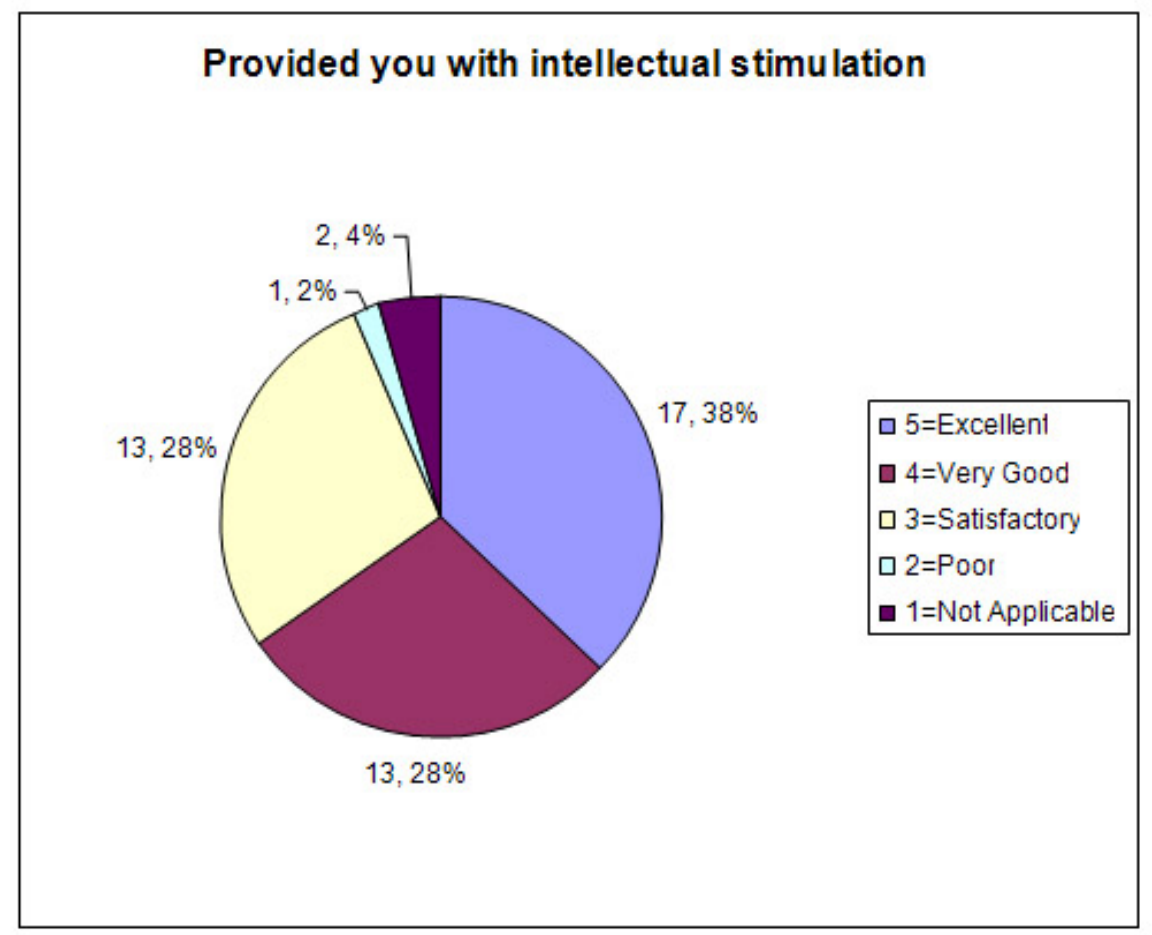


Figure 7. Mobile learning outcomes survey

\section{Fostered interaction and teamwork among class members}

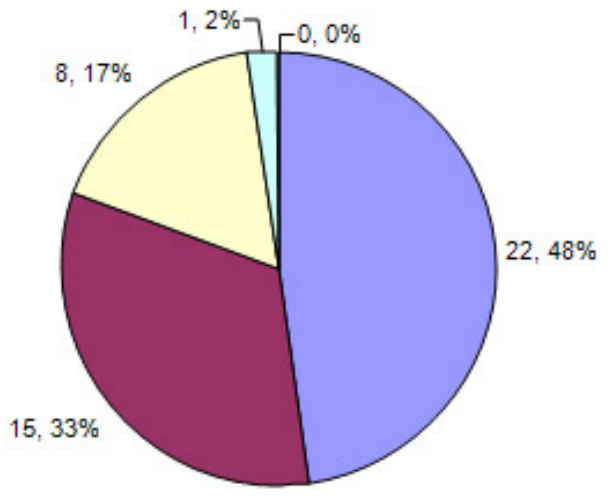

Figure 8. Mobile learning outcomes survey

\section{Fostered your creativity}

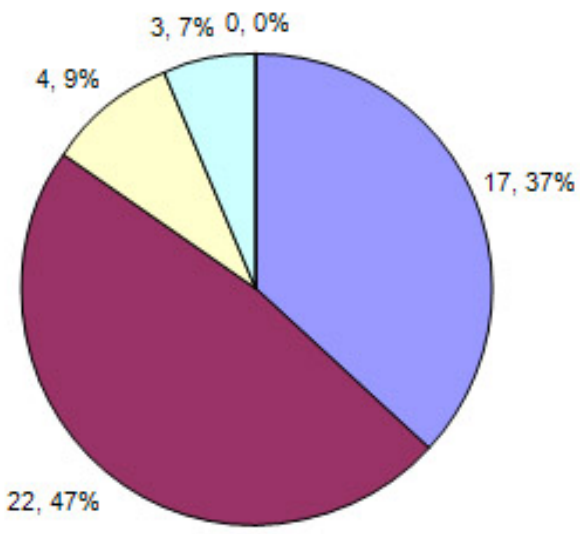

$\square 5=$ Excellent $\square$ 4=Very Good $\square$ 3=Satisfactory $\square 2=$ Poor 
Figure 9. Mobile learning outcomes survey

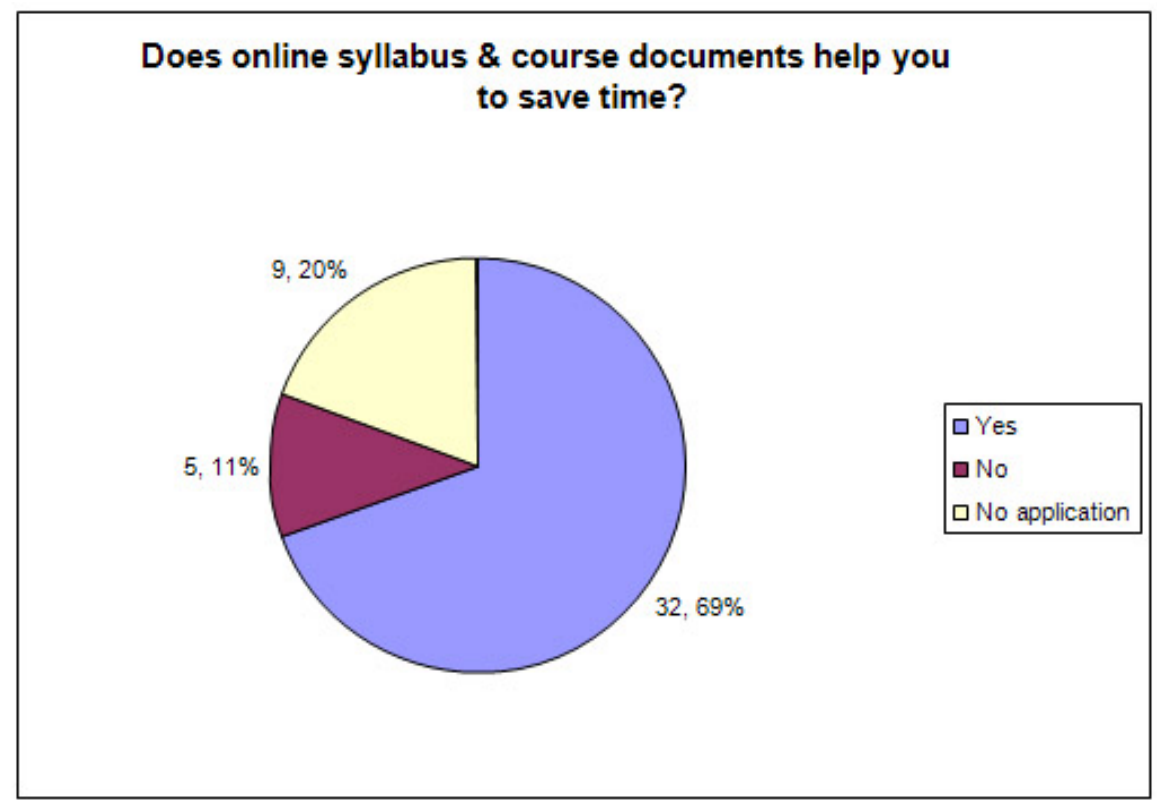

Figure 10. Mobile learning outcomes survey

\section{Does online discussion board help you to save time?}
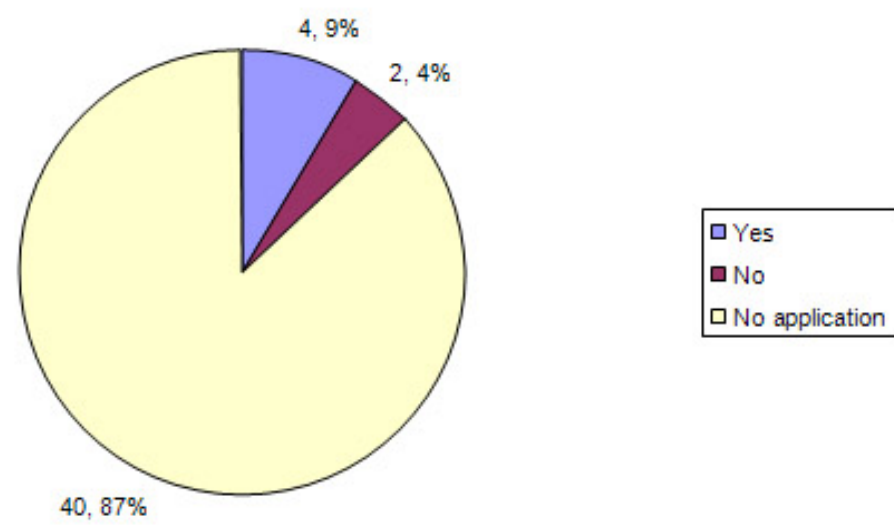
Figure 11. Mobile learning outcomes survey

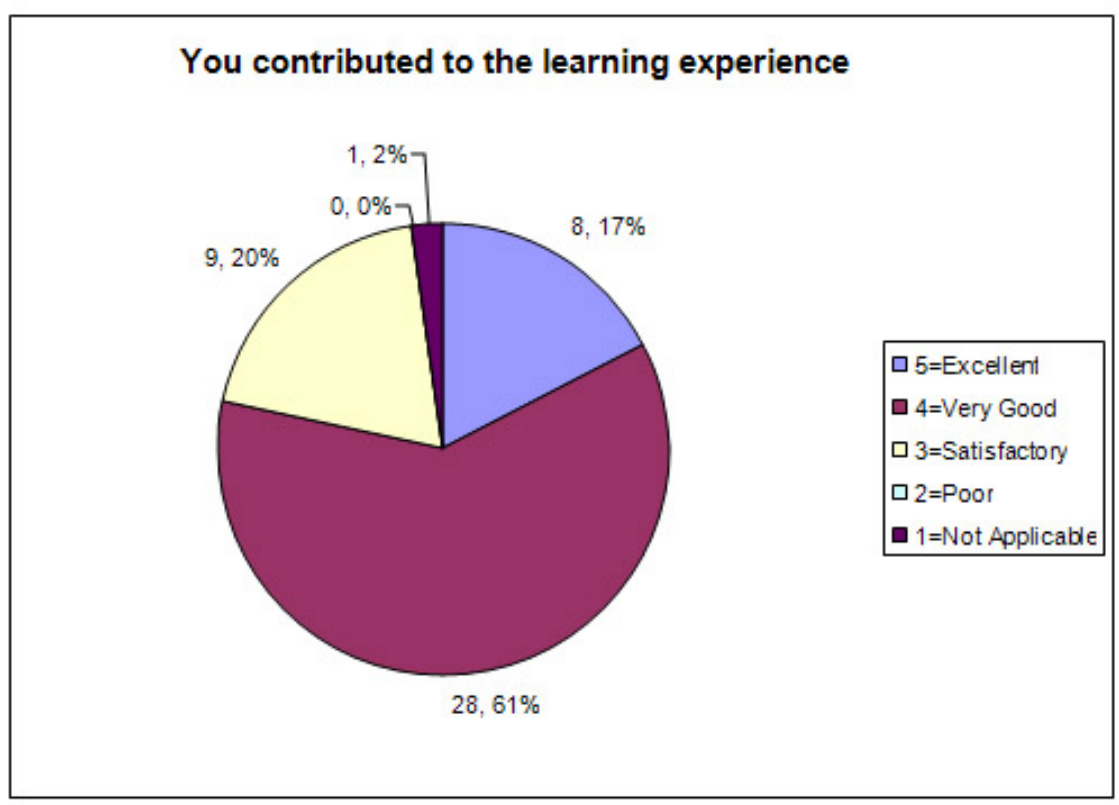

Figure 12. Mobile learning outcomes survey (See short answers below)

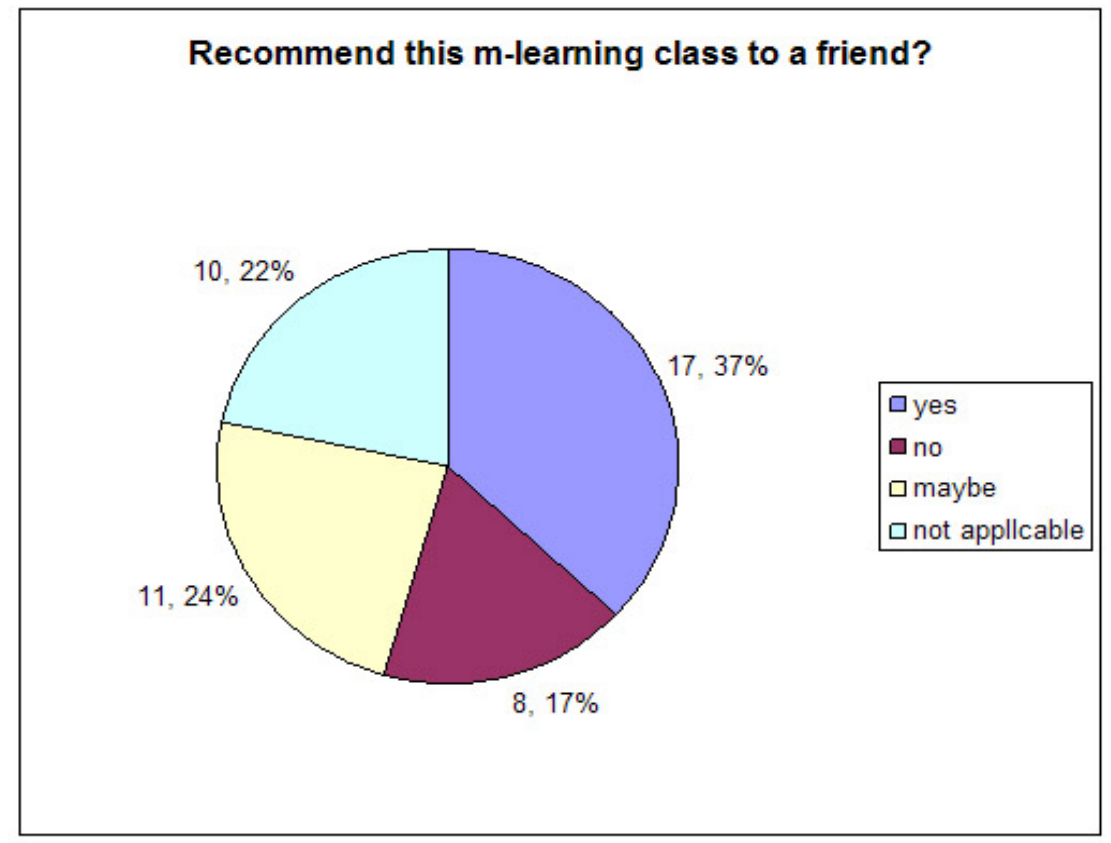




\section{Short Answer Qualitative Survey}

\section{Would you recommend this m-learning class to a friend? Why or why not?}

Responses from participants to this open ended question:

1) Yes, it was a lot of fun I really enjoyed the class.

2) Yes, because it ends up saving stress by being able to access materials anytime,

3) It's in the beginning phases and has wrinkles that need to be ironed out, but I see it as a very positive future method.

4) Only if the m-learning was more organized.

5) If my friend had the capability to use m-learning then I would recommend it because it does save time for the users.

6) Yes, helpful

7) I couldn’t say. If they are good at phones, yes.

8) Yes, because you learn.

9) No, to much hassle \& Stress I trying to figure out new things online is easier.

10) Yes, It helped me save time, and assisted me in my learning.

11) Yes and No. I personally did not use the mobile learning very much I was a mobile learner but did not use it as planned.

12) Good teacher, m-learning I didn’t really like.

13) No, makes the class more difficult.

14) Yes.

15) Not the m-learning, but the class yes. M-learning really just takes more time when you could just use the phone or email.

16) Yes, if it were a bit more organized.

17) I'm not sure! The class content was great but I couldn't follow the organization. It was hard for me to keep up.

18) Yes, Very interesting. 
19) Yes, because if you have a busy life m-learning actually works around your schedule and you have $24 / 7$ access to it.

20) Sure, if wasn’t hard and it helped get things done faster.

21) No, not easily accessible.

22) Yes, I was not affected by the m-learning portion.

23) No, too difficult, need to have phone’s provided.

24) Yes and No. It may be confusing if you do not know how to work technology.

25) Yes, only if everything goes as planned.

26) Nope, because I didn't use it.

27) Sure, it was an interesting experience, and the flexibility made it very every to work with.

28) Yes, I thought that I learned new things I did not know of before.

29) If they liked children’s literature and didn’t mind the disorganization.

30) Yes, It everything worked out correctly.

31) If you are good with technology go for it other than that you may struggle and spent more time than same time. You don't have to remember where you left your papers you have them in email or something end to always have your phone.

32) No, because it was too much all over the board. May be if it had worked, I would be more positive. However for me it was too much of a hassle.

33) I felt very confused in this class and would probably not recommend it. I am very technological but did not care for the class.

34) The concept sounds really useful, but since we couldn't use the phones fully I couldn't tell. Overall, the concept sounds great.

35) Not really b/c it seemed easier just to talk in class and share ideas with everyone.

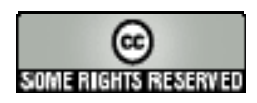

